\title{
NAS ONDAS DO RÁDIO: A EDUCOMUNICAÇÃO COMO UMA PRÁTICA PARA A CIDADANIA
}

\begin{abstract}
PÂMELA ANDRADE DE MORAES UNIVERSIDADE REGIONAL DO NOROESTE DO RIO GRANDE SUL IJUÍ, RIO GRANDE DO SUL, BRASIL PAMELA.ANDRADE.MORAES@GMAIL.COM

NELSON JOSÉ THESING UNIVERSIDADE REGIONAL DO NOROESTE DO RIO GRANDE SUL IJUÍ, RIO GRANDE DO SUL, BRASIL NELSON.THESING@UNIJUI.EDU.BR

LAURIANE TRAMONTINA ZENI UNIVERSIDADE REGIONAL DO NOROESTE DO RIO GRANDE SUL IJUÍ, RIO GRANDE DO SUL, BRASIL LAURIANETZ@HOTMAIL.COM
\end{abstract}

HTTP://DX.DOI.ORG/10.5902/2316882X29099 
NAS ONDAS DO RÁDIO: A EDUCOMUNICAÇÃO COMO UMA PRÁTICA PARA A CIDADANIA

Resumo: Educar é sem dúvida nenhuma comunicar. Deste modo, a educação provoca a inovação, pois, os agentes envolvidos no processo institucional, aprimoram suas capacidades, e atuam de forma coletiva na investigação dos processos da organização e de sua interação com o meio. A educomunicação não apenas liga as áreas da educação e comunicação, mas também, propõem ações importantes de cidadania.

Palavras-chave: Rádio Escola; Educomunicação; Cidadania.

\section{EN LAS ONDAS DE LA RADIO: LA EDUCOMUNICACIÓN COMO UNA PRÁCTICA PARA LA CIUDADANÍA}

Resumen: Educar es sin duda alguna comunicar. De este modo, la educación provoca la innovación, pues, los agentes involucrados en el proceso institucional, mejoran sus capacidades, y actúan de forma colectiva en la investigación de los procesos de la organización y de su interacción con el medio. La educomunicación no sólo vincula las áreas de la educación y comunicación, pero también, proponen acciones importantes de ciudadanía.

Palabras clave: Radio Escuela; Educomunicación; Ciudadanía.

IN RADIO WAVES: EDUCATION AS A PRACTICE FOR CITIZENSHIP

Abstract: To educate is undoubtedly to communicate. In this way, education provokes innovation, because the agents involved in the institutional process, improve their capacities, and act collectively in the investigation of the processes of the organization and its interaction with the environment. Educommunication not only links the areas of education and communication, but also, they propose important actions of citizenship. Keywords: School Radio; Educommunication; Citizenship. 


\section{TEORIZANDO}

Para além das diferentes funções que as práticas de educação possam assumir, coloca-se a ela o desafio da produção do conhecimento, da oportunidade do pensamento crítico frente à sociedade ou, de acordo com a expressão de Lévy, da inteligência coletiva. Essa inteligência apresenta o reconhecimento e o enriquecimento mútuos das pessoas.

Marques (1996, p. 14), destaca a importância do diálogo, quando declara:

[...] a educação se cumpre num diálogo de saberes, não em simples troca de informações, nem em mero assentimento acrítico a proposições alheias, mas na busca do entendimento compartiIhado entre todos os que participam da mesma comunidade de vida, de trabalho, de uma comunidade discursiva de argumentação.

Esse processo assemelha-se as ações de cooperação, que segundo Frantz (2001) oportuniza um processo de interlocução de diferentes vozes que se aproximam, solidarizam-se, identificam-se para a construção de espaços comuns de atuação, sem, no entanto, renunciarem a si mesmas, preservando, assim, as condições e as posições do diálogo de seus saberes, de suas experiências de vida.

Ocorre nesse contexto a promoção da cidadania, nos mais variados ambientes, não sendo algo exclusivo de grandes centros urbanos, ou de uma parcela pequena da população, mas sim, inserida na promoção do debate local, na resolução dos problemas cotidianos das pequenas comunidades, desde o micro espaço até o macrocampo de discussões, chegando aos poderes de representações.

Nesse momento em que rapidamente a tecnologia evolui, a educação como detentora de espaços importantes de debates, precisa adaptar-se, pois o perfil de estudantes desta nova geração mudou, ao passo, que o próprio contexto cidadão evoluiu. Atualmente, os jovens, comunicam seus descontentamentos ou/e também suas alegrias em comentários nas redes sociais online, que abrigam grande parcela da população. A educação como elemento importante contribuinte para o fortalecimento da sociedade democrática de direito deve adequar-se aos novos tempos e meios, a ela não pertence mais o quadro negro e o giz na mão do professor, a cultura difere, e o aluno mudou seu perfil cultural de aprendizado,

Rev.Cad.Comun. Santa Maria, v.22, n.1, art 1, p.15 de 31, jan/abr.2018 
CADERNOS DE COMUNICAÇÃO

UNIVERSIDADE FEDERAL DE SANTA MARIA

como explica Soares (2011, p.16):

"O discurso sobre a educação que a define como base da construção da democracia moderna e do progresso dos povos está sendo substituído pelo discurso sobre a excelência e a irreversibilidade da informação. Em outros termos, há uma valorização social do mundo da comunicação e uma negação do mundo da educação tradicional”

É importante destacar que os elementos teóricos destas duas vertentes, educação e comunicação, foram analisados conjuntamente, para buscar uma compreensão deste relacionamento, e assim, nasce um recente campo de conhecimento, denominado por "educomunicação":

Trata-se de uma expressão que não apenas indica a existência de uma nova área que trabalha na interface comunicação e educação, mas também sinaliza para uma circunstância histórica, segundo a qual os mecanismos de produção, circulação e recepção do conhecimento e da informação se fazem considerando o papel de centralidade da comunicação (CITELLI; COSTA, 2011, p.8)

Os estudos de Freire na década de 1960 no Brasil fortaleceram o desenvolvimento do pensamento de que promover o trabalho educacional é fazer comunicação e desenvolver o diálogo social. O autor compreendia a educação como um processo coletivo de aprendizado, no qual os sujeitos interagem, expressam seus variados pontos de vistas sobre um mesmo assunto, ou então, assuntos diferentes, e buscam nesse processo a resolução de problemas, que muitas vezes não seriam enfrentados da mesma forma e se prolongariam se a dialogicidade fosse evitada.

Seres humanos não conseguiriam viver em plenitude sem educação, muito menos sem comunicação, é elemento indispensável à vida em comunidade, a qual, cada vez mais se torna tecnológica e altamente interativa. A sociedade demanda uma escolarização humanizada, onde cidadãos formam o protagonismo essencial para a vida em grupos. Na escola é que se desenvolvem competências como liderança, cooperação, reflexão crítica e visão futurista. Neste espaço, denominado escola, os encontros acontecem e precisam fortalecer a cultura de suas comunidades. São jovens, adultos, meninos e meninas, homens e mulheres de diferentes origens, educados por variados costumes, com singulares formas de aprendiza-

Rev.Cad.Comun. Santa Maria, v.22, n.1, art 1, p.16 de 31, jan/abr.2018 
do que reunidos em um mesmo local necessitam de oportunidades para exercitar relacionamentos diversos por meio de variados modelos de comunicação.

Existem muitas reflexões para definir o que realmente a educação significa, por ser um fenômeno complexo da existência humana. Libâneo (1998, p.22) define a ação de educar como um conjunto das ações, processos, influências, estruturas, que intervêm no desenvolvimento humano de indivíduos e grupos na sua relação ativa com o meio natural e social, num determinado contexto de relações entre grupos e classes sociais. $\mathrm{E}$ nessa atuação forma-se um campo, que segundo o autor é "um campo de atuação pedagógica".

Nestas relações são entrelaçados saberes, não podendo ser de domínio exclusivo do professor, diretor ou determinado grupo, mas da escola como um processo de cooperação, troca e argumentação. Para melhor compreender a prática educativa com a comunicação, é importante que seja questionada sua utilização social, assim, descobriremos, a partir, de quem a prática, como pode existir contribuição ao contexto da cidade em que a escola é inserida, no estado, e no país.

É importante destacar que a partir da inserção das Tecnologias de Informação e Comunicação - TICs a escola deixa de ser a fonte privilegiada das informações, mas torna-se a fonte que detém credibilidade para validar os conteúdos. Nesse sentido, o trabalho educomunicativo busca colocar o aluno no centro dos debates, e fazê-lo produzir subsídios que contribuam com as discussões dos mais variados temas, que a escola proporcione ao jovem estudante o esclarecimento de questões presentes na mídia, na comunidade, na própria família. O processo de educação atualmente não ocorre somente dentro da sala de aula, mas é na sala de aula nela que o conhecimento precisa ser moldado para a reflexão crítica.

Os modelos tradicionais de educação e que ainda convivemos estão classificados por três eixos na visão de Citelli (2004), sendo esses: hierarquia, coerção e exclusão. Se continuarmos a seguir esses princípios seremos levados e não levaremos a formação cidadã competente. O professor ainda é uma autoridade detentora de poder e passível de punir, mas que educação é essa, que se dá nas bases do medo de ser reprovado, no medo de errar ao afirmar suas posições. A educação não se cumpre no ordenar e fazer, mas sim, no acompanhamento, orientação, e na comunicação.

Rev.Cad.Comun. Santa Maria, v.22, n.1, art 1, p.17 de 31, jan/abr.2018 
A educomunicação propõe a abertura de propostas, com o objetivo de elaboração de novas políticas, as quais devem acompanhar com mais eficiência o processo de desenvolvimento tecnológico do século que vivemos. É importante perceber que o sucesso ou fracasso do estudante dependerá muito do quanto dialogou entre seu grupo, colegas e professores. Existem ainda, casos de professes que não permitem que seus alunos conversem ou o interrompam durante a explicação do conteúdo, tornado a aula autoritária e monótona, sem acréscimo cultural aos ouvintes, pois, dentro de uma sala de aula existem grandes particularidades de aprendizagem, há alunos que são mais auditivos, outros visuais, alguns alunos precisam tocar em materiais para compreender o conteúdo, não existe fórmula mágica, nem mesmo, receita de bolo para o processo de ensino-aprendizagem, mas existe ferramentas da comunicação e métodos que podem contribuir para a efetivação da escolarização e formação competente dos indivíduos.

Quando o professor torna-se um libertador consegue assumir um direcionamento eficiente para educar, não sendo autoritário nem sem responsabilidade sobre o contexto. Uma aula libertadora "ilumina a realidade" conforme as palavras de Freire (2000, p. 204). A aula libertadora estimula o educando a desvendar a manipulação real e os mitos da sociedade. E nesse "desvendamento" mudam-se as compreensões da realidade, a nossa percepção. A realidade atual ainda caminha longe da necessidade dos alunos, os estudantes que nasceram na era digital, conhecidos como "geração y", ingressam na escola com uma grande bagagem de informações, pois desde bebes nascem conectados aos aparelhos eletrônicos mais variados. Esses alunos possuem novas necessidades, os conteúdos programáticos, precisam ser aprendidos sim, como; história, geografia, matemática, entre outras disciplinas. Mas em especial, precisam compreender como esses conteúdos estão sendo aproveitados nas suas relações sócias, e isso é possível com auxílio de mecanismos tecnológicos como os que os cercam.

Para isso, o educador precisa atualizar-se, talvez a palavra do momento aos professores, seja, planejamento. Planejar aulas envolventes, apresentando os conteúdos, as informações de forma que oportunize a reflexão, a participação, o questionamento e por fim o entendimento. Também, de forma muito importante, o educador precisa atenção ao fato de que a transformação não é empregada apenas às mudanças de méto-

Rev.Cad.Comun. Santa Maria, v.22, n.1, art 1, p.18 de 31, jan/abr.2018 
dos de ensino ou de técnicas, mas deve ocorrer no relacionamento, na humanização do conhecimento, na promoção dos vínculos e no emprego da cidadania. E para isso ocorrer de forma plena o professor deve ficar atento aos novos formatos de comunicação.

Para Kaplún (1998) a comunicação não pode ser percebida como um mero instrumento midiático e tecnológico, e sim, antes de tudo, como um componente pedagógico, componente esse que: "enquanto interdisciplina e campo de conhecimento para a comunicação educativa, entendida desse modo, convergem uma leitura da pedagogia a partir da comunicação e uma leitura da comunicação a partir da pedagogia" (KAPLÚN, 1998, p. 69).

Há mais de três décadas que a educomunicação é discutida, sendo um campo conhecido como de intervenção social, pois se apresenta com autonomia. Soares (2011) diz que essa autonomia se dá, pois, esse novo campo possui filosofia própria, história e também reconhecimento da sociedade, sendo um campo de mediações "há necessidade de teorização e de reflexão crítica", assim, será possível a constituição de projetos políticos de interesse público, tornando a educomunicação conforme Soares (1999, p.57) um novo espaço de luta material e discursiva.

\section{O RÁDIO COMO INSTRUMENTO DE EDUCAÇÃO}

É importante destacar que dentre as muitas experiências tecnológicas desenvolvidas ao longo dos tempos, o rádio marcou o século XIX. Esse meio de comunicação não perdeu seu espaço, apesar do surgimento da televisão e também recentemente da internet, pois, continua um espaço de alcance das discussões locais das comunidades em que é inserido. Sendo um meio integrante dos mais variados grupos sociais e um dos promotores da cidadania, pois seu espaço oportuniza as reflexões coletivas, sendo possível, informação, diversão e cidadania de forma rápida, direta e efetiva.

O rádio é um instrumento muito particular de difusão do conhecimento, pois, até mesmo com a implantação de altas tecnologias, essas, caminham ao seu favor. Atualmente, se ouve ouvir rádio no celular, no tablet, computador e nos mais variados ambientes, demonstrando como esse meio também pode ser democrático, no sentido pleno de suas funções, sendo de fácil acesso por todas as classes sociais e espaços diferentes e 
por meio de mecanismos de informação complexos. Uma rádio no ambiente escolar, quando assumido pela instituição, necessita de um grande engajamento social, precisa de acompanhamento e tomada de decisões coletivas, por direção, coordenação pedagógica e em especial pelos professores que realizarão suas atividades de ensino focadas na utilização desta ferramenta da comunicação e agora também da educação.

Conforme Raddatz (2015) é por meio da execução de um projeto de rádio escolar, ou outro mecanismo como jornal, blog ou uma web TV, que o aluno vai experimentar entender e avaliar as ferramentas e as etapas necessárias para que a informação se constitua um conteúdo midiático: captação, produção, edição, difusão e recepção da informação. Um trabaIho de colaboração, com a junção de práticas sociais importantes para o desenvolvimento, educação e cooperação, que, sob certos aspectos, uma contém a outra, declarou Frantz (2001).

Promovendo assim, uma educação que se preocupa com a cidadania, como declara Raddatz (2015, p.93) "a educação preocupada com a cidadania é aquela que propicia vivências cotidianas de interação com a realidade, que abre a caixinha dos conteúdos para a relação com o social e o político, estimulando a descoberta e a participação do sujeito na sociedade". Quando o indivíduo sente-se participante do processo e não somente mero espectador é possível conhecer a realidade que o cerca, opinar sobre ela, e sistematicamente busca transformá-la e por consequência meIhorar suas condições.

O rádio escolar humaniza o processo de aprendizagem, pois, sua ação o torna coletivo, amplo e dinâmico, coloca o ensino como uma estrada longa e grande, mas permeada por muitos caminhos e possibilidades. Acrescenta credibilidade e ação ao processo de educação, tornando esse cidadão, colaborativo e opinativo. O aluno recebe informações, mas também a produz e emite aos demais por um canal importante de difusão de conhecimento.

É importante contextualizar o veículo rádio com o rádio desenvolvido no âmbito escolar, pois desde seu surgimento o rádio é promotor de ações que interfere nas políticas sociais e comunitárias. Sendo visível sua ação comunicativa como vetor de transformação social, e isso ocorre pela apropriação que o ouvinte faz de suas mensagens, pois nas comunidades como também dentro do rádio na escola, o ouvinte não é mais passivo, pois não apenas recebe a informação de forma neutra, nesse momento já

Rev.Cad.Comun. Santa Maria, v.22, n.1, art 1, p.20 de 31, jan/abr.2018 
reflete sobre sua abordagem crítica da realidade, e logo após, emite novas informações. Então, o receptor agora também é percebido como produtor de conteúdo.

Em muitos grupos da sociedade o rádio é o único meio de acesso a informações de sua comunidade. Por essa aproximação com as realidades locais, torna-se um meio de transmissão de valores culturais e sociais. As pessoas na faixa etária dos 40 anos cresceram ouvindo rádio. Atualmente o novo ouvinte precisa sentir-se pertencer ao veículo de comunicação, e nada melhor do que ser produtor deste dentro do seu ambiente escolar. Para Martín-Barbero o popular consegue infiltrar-se no massivo, mantendo suas tradições e culturas.

Passamos por um momento de mudanças na comunicação e em todo o seu processo, pois, vivenciamos períodos de adaptações, com novos modelos de transmissão e recepção de informações, sejam elas dos mais variados segmentos, culturais, esportivas ou noticiosas. Na escola não é diferente, esses novos tempos exigem uma nova roupagem para a apresentação dos conteúdos, como: história, geografia, matemática entre outros.

Atualmente o ouvinte de uma rádio convencional possui a mesma capacidade de produção de conteúdo, notícias, música e anúncios que profissionais da área, pois existe um novo mundo possível com a era da internet. Assim, os jovens como educandos, também se tornam educadores por meio do rádio, na medida em que fornecem novos conteúdos ao espaço escolar. Podemos entender que o rádio não é somente um veículo de comunicação de massa. O rádio faz pensar, sendo um veículo popular que divulga variadas informações e conteúdos com forte impacto. E isso, oportuniza aos estudantes facilidade no entendimento e aproximação com a realidade em que vivem.

\section{EDUCOMUNICAÇÃO E PRÁTICA CIDAdÃ}

A educação é um elemento de formação cidadã importante, em especial ao considerar as possibilidades e oportunidades que proporciona aos que tem acesso. Da mesma forma ocorre com a comunicação, a qual, por meio, de suas práticas oportuniza o conhecimento e uso adequado de procedimentos, investimentos e ações para a conquista da informação.

Para acompanhar como a educação comunica-se com as demais áreas

Rev.Cad.Comun. Santa Maria, v.22, n.1, art 1, p.21 de 31, jan/abr.2018 
da sociedade colaborativa, é importante considerar os processos de evolução tecnológica existentes na atualidade. Depois da era industrial foram desenvolvidas novas tecnologias que aproximam visões de mundo com apenas um click. Acompanhar essa evolução tornou-se um desafio que pode ser perfeitamente aproveitado pela comunicação, inovando processos de relacionamento no ambiente educacional e despertando o espírito cidadão.

Na perspectiva de apostar na vinculação da educação a possibilidade de acolher as novas gerações e contagiá-las com auxílio da comunicação, torna-se imprescindível, tanto para a (re)construção do sentido de humanização quanto para a (re)educação dos desafios apresentados no contexto de mudanças regionais, a análise periódica destes processos. Educar é sem dúvida nenhuma comunicar, deste modo, a educação provoca a inovação, pois, os agentes envolvidos no processo institucional, aprimoram suas capacidades, e atuam de forma coletiva na investigação dos processos da organização e de sua interação com o meio, oportunizando questionamentos constantes de seus modelos mentais e assim, criando ambientes seguros para ampliação de processos educativos.

A educação necessita ser percebida como libertadora, desvinculada do modelo de reprodução das ações repetidor e deve promover o incentivo para a criação do novo, oportunizando ideias visando o benefício do todo, e assim, diminuindo as desigualdades. Em oposição ao pensamento bancário da educação, Paulo Freire (2005) propõe que a educação seja pensada de forma dialógica, que considere o saber do educando e que esse seja motivado a participar do processo educacional. Essa participação é medida pela comunicação que esclarece os objetivos buscados e aproxima as realidades, permitindo uma consciência do ser, estar e agir no mundo.

A valorização das experiências de cada indivíduo, assim como, da cultura local, da consciência e a compreensão das necessidades e limitações de cada ser, humaniza a prática do ensino. E assim, o processo de aprendizagem se aproxima da essência do pensamento de auxílio mútuo.

O pensar do educador somente ganha autenticidade na autenticidade do pensar dos educandos, mediatizados ambos pela realidade, por tanto, na intercomunicação. Por isso, o pensar daquele não pode ser um pensar para estes nem a estes impostos. Daí que não possa ser um pensar no isolamento, na torre de marfim, mas na e pela comunicação, em torno,

Rev.Cad.Comun. Santa Maria, v.22, n.1, art 1, p.22 de 31, jan/abr.2018 
repitamos de uma realidade (FREIRE, 2005, p.74).

Morin (2011) ao dimensionar a educação da atualidade apresenta o ensino como universal e centrado na condição humana. O autor afirma que vivenciamos a era planetária, esse momento, conduz os seres humanos ao encontro de um reconhecer-se em sua humanidade. Assim:

O homem somente se realiza plenamente como ser humano pela cultura e na cultura. Não há cultura sem cérebro humano (aparelho biológico dotado de competência para agir, perceber, saber, aprender), mas não há mente (mind), isto é, capacidade de consciência e pensamento sem cultura. A mente humana é uma criação que emerge e se afirma na relação cérebro-cultura (MORIN, 2011, p.47 e 48).

O filósofo e sociólogo Habermas (1990) afirma que é através do agir comunicativo que os agentes se constituem, ou seja, a linguagem que os alunos, professores e colaboradores articulam o "que sou" nas relações sociais provoca o raciocínio de como poderão agir coletivamente e designar o "que somos". É importante que haja meios para prover essa comunicação, que ocorra de forma alinhada aos princípios da educação.

Na teoria de Luhmann (1999), a sociedade é pura comunicação e toda a comunicação é sociedade. A comunicação não pode ser afetada por nada que exista fora dela. A sociedade é o universo de todas as comunicações possíveis. Dentro do processo de ensino aprendizagem, a comunicação insere-se, além dos meios de comunicação, também, nas estruturas comunicativas discursivas e narrativas dos indivíduos integrantes do meio educacional. E nesse contexto podem ser observados elementos de representatividade comunicacional, os quais produzem identidade dos sujeitos pertencente à organização.

Quando abordamos questões relacionadas ao empoderamento enunciamos a consciência de si e do ambiente, provocando uma autonomia que segundo Honneth (2003, p.158) "aumenta também como cada etapa de respeito recíproco". Assim, é possível promover o autoconhecimento dos papéis desempenhados pelos indivíduos, conforme Cabral (2015, p. 25):

O autoconhecimento, segundo a psicologia, significa o conhecimento de um indivíduo sobre si. A prática de se conhecer melhor faz com que uma pessoa controle suas emoções, independente de serem positivas ou não. Tal controle emocional provocado pelo autoconhecimento pode evi-

Rev.Cad.Comun. Santa Maria, v.22, n.1, art 1, p.23 de 31, jan/abr.2018 
tar sentimentos de baixa autoestima, inquietude, frustrações, ansiedade, instabilidade emocional e ocasionando resoluções produtivas e conscientes acerca de seus variados problemas.

Embora o ambiente social por vezes seja individualista, quando existe a proposta de sucesso pessoal, os seres humanos necessitam viver em grupos. E esses grupos conduzem a união para alcançar objetivos comuns, os quais seriam traçados com dificuldades se a tentativa de conquista fosse de forma individual. Com a compreensão destas características humanas, refletidas dentro das relações de educação pode-se observar como a comunicação exerce papel fundamental no entendimento do processo de aprendizagem. Alunos, professores e a comunidade comunicam-se, pois, essa educação, atua em todos os níveis do indivíduo. A educomunicação reflete autoestima, motivação, envolvimento, fidelidade, participação e reciprocidade.

Quando apresentamos o espaço educacional, elencamos departamentos, com o pedagógico, secretarias, sala de professores, biblioteca, direção, refeitórios, entre outros. São espaços de socialização, onde indivíduos permanecem durante grande parte do tempo em atividades de grande envolvimento. Todas as pessoas inseridas na escola, como secretários (as), merendeiros (as), bibliotecários (as) integram o processo educacional, fazem educação, não de forma pedagógica, mas sim, institucional.

A educomunicação busca essa integração dinâmica entre os pólos educacionais, conscientizando todos os envolvidos no educandário que são de fato produtores de educação. A partir da realização de um projeto, como o Rádio, Tecnologias e Empreendedorismo na Escola, a compreensão e acima de tudo o engajamento de todos para o êxito do projeto é algo decisivo em seu processo de implantação e manutenção. Quando existe participação coletiva, existe projeto, existe diálogo de saber e existe promoção da cidadania.

A educação deste século deve primar pela perspectiva do professor que construa sua dimensão educacional baseado no que o estudante não sabe e no que precisará saber. Esse processo Freire (2005) descreve como "universo vivencial do aluno", sendo a leitura de mundo que o jovem pode ter, pois não se podem subestimar os alunos, esses não são mentes vazias, já possuem bagagens culturais densas, o que deve ser considerado pelo professor na busca de sua inovação didática.

O mundo desejado de uma vivência coletiva feliz dentro do ambiente

Rev.Cad.Comun. Santa Maria, v.22, n.1, art 1, p.24 de 31, jan/abr.2018 
escolar e no âmbito das relações sociais não pode ser encarado com uma utopia, mas sim um elemento de poder para conquistas, conforme Cortella (2015, p.24) "o que é imaginado, aquilo que somos capazes de projetar como desejo de futuro que nos faça crescer".

O autor ainda destaca que nós humanos somos animais gregários, por isso vivemos agregados. Existem também situações que segregamos, mas na maior parte do tempo praticamos a congregação, no sentido pleno de vivermos juntos. Essa perspectiva significa muito a necessidade humana de formar estruturas de relacionamentos que conduzam a boa convivência, e parte desta estrutura ocorre no âmbito das formas como se comunicam esses indivíduos em suas sociedades.

$\mathrm{Na}$ escola, o professor comunica ao aluno, o diretor comunica ao professor, o aluno comunica ao outro aluno, que retorna essa comunicação ao professor e formam-se estruturas comunicacionais importantes em rede. Quando apresentamos dentro desta estrutura novos elementos para ampliação desta comunicação como rádio, fotografia, vídeo e internet, oportunizam-se desenvolvem-se outras condições para o fortalecimento democrático no ensino.

Esses elementos criam importantes conexões de compaixão. Um exemplo: o aluno precisa confeccionar uma chamada ao programa de rádio sobre a importância do uso racional da água, ou então como utilizar as lixeiras seletivas do colégio de forma adequada, nesse momento, o jovem dissemina o ideal de zelo por sua vida e pela vida dos demais integrantes daquela instituição. Para Cortella (2015) esse sentido de "compaixão" dentro do processo educacional se liga com a noção de pathos, aquilo que é uma afecção, aquilo que move, comove e afeta, demonstra propósito coletivo e responsabilidade social.

A compaixão gera o movimento de partilha, que também é perfeitamente aproveitado no programa da rádio escola, pois é necessário um locutor, repórter, sonoplasta, editor, e todos esses devem partilhar informações, dialogar com os seus pares e interagir entre si para prover a qualidade do material final apresentado. Essa colaboração nos remete ao conceito de cidadania. A cidadania está presente neste processo educomunicacional, pois também necessita de colaboração dos sujeitos para a sua promoção. A educação é uma das vertentes de colaboração para que a democracia se apresente no sentido reflexivo de sua palavra e origine cada vez mais cidadãos preocupados e atentos com os avanços, partici-

Rev.Cad.Comun. Santa Maria, v.22, n.1, art 1, p.25 de 31, jan/abr.2018 
pativos aos processos de desenvolvimento e integrados com os fatos do mundo e que o cercam.

Conforme Frantz (2001) não é, portanto, a educação, a pedagogia, um fenômeno neutro:

[...l "politizam-se" as práticas educativas e cooperativas no sentido da construção de novos espaços e oportunidades sociais, de novos conhecimentos e saberes, e não no sentido da introdução aos espaços sociais, às oportunidades, conhecimentos e saberes já existentes e dominantes] (2001, p.247).

Os nativos digitais estão conectados a um mundo totalmente diferente do que a escola proporciona no momento atual. $E$ ao se encontrar com esse ambiente escolar do passado, o aluno fica desmotivado. As tecnologias surgem como elementos de impulso ao apreender, mediadoras de conhecimento. E com a pose destes novos mecanismos tecnológicos, as escolas precisam se reinventar.

Freire (1977, p.66) afirma que "não há um "penso", mas um "pensamos". É o que "pensamos" que estabelece o "penso" e não o contrário. E assim, a educomunicação busca essa pluralidade de diálogo dentro da sala de aula, pois não é somente o professor que articula a apresentação didática, mas os alunos também devem refletir sobre os enunciados. Assim, educando e educador constrói um saber coletivo, e o professor deve sempre instigar a curiosidade do jovem aluno, para que esses se tornem inquietos e críticos.

Soares (1995) explica que o papel do educomunicador é o de ser agente cultural, atuante em espaços formais e não formais, e também atuar como gestor de processos comunicacionais:

Um agente cultural com conhecimentos suficientes no campo da educação e com o manejo profundo das teorias, linguagens e técnicas da comunicação. Sobretudo, um profissional com capacidade de criação, para dar vida e sentido aos recursos colocados pela civilização a serviço de toda a humanidade. Trata-se de um verdadeiro gestor de processos comunicacionais: faz nascer e gerencia projetos e produtos na área da comunicação nos espaços de ensino formal e não forma. (SOARES, 1995, p.45).

De acordo com Kaplún (1983) existem três modelos de educação e comunicação divididos em: pedagogia transmissora, persuasora e proble-

Rev.Cad.Comun. Santa Maria, v.22, n.1, art 1, p.26 de 31, jan/abr.2018 
matizadora. A primeira prima pelos conteúdos com objetivo que o aluno aprenda. A segunda foca nos efeitos, objetivando que o aluno opte pelas condutas desejadas e a terceira apresenta a importância do processo de transformação da pessoa e de sua comunidade.

A educomunicação foi pensada inicialmente como uma educação para os meios, mas estudos comprovaram que sua concepção passou, além disso, sendo percebida como importante componente de promoção da cidadania, por meio das oportunidades que carrega para a análise crítica dos conteúdos e promoção do diálogo.

A educomunicação trabalha a questão do uso das TICs no ambiente escolar. Matín-Barbero (2003) define a educomunicação como ecossistemas comunicativos em que haveria uma conexão entre todos os elementos que implicam na educação e na comunicação. Assim, o autor explica que é preciso olhar esse contexto para:

[...] pensar no ecossistema comunicativo que constitui o entorno educacional difuso e descentrado em que estamos imersos. Um entorno difuso, pois está composto de uma mescla de linguagens e saberes que circulam por diversos dispositivos mediáticos, mas densa e intrinsecamente interconectados; e descentrados pela relação com os dois centros: escola e livro que a vários séculos organizam o sistema educacional (BARBERO, 2003, p.67).

Fischer (2005) acredita que o professor dentro da sala de aula deve apresentar experiências e modelos que servirão para o resto da vida das crianças, e isso é possível quando utilizamos mídias:

\begin{abstract}
O trabalho pedagógico insere-se justamente ai, na tarefa de discriminação que educadores e estudantes precisam exercitar cotidianamente em sua prática pedagógica, e que, ao meu ver, inclui desde uma fraca abertura à fruição (no caso, de programas de TV, comerciais, criação de vídeos, filmes veiculados pela TV, etc.) até um trabalho detalhado e generoso sobre a construção de linguagem em questão e sobre a ampla gama de informações reunidas nesses produtos, sem falar nas emoções e sentimentos que cada uma das narrativas suscinta no espectador. (FISCHER, 2005, p.158)
\end{abstract}

A autonomia da escola é relativa, existe terreno para construção do necessário, mas sem desconsiderar as determinações que a escola tem

Rev.Cad.Comun. Santa Maria, v.22, n.1, art 1, p.27 de 31, jan/abr.2018 
nem supor que ela possa fazer qualquer coisa. Mas o fato de poder ser feito não nos basta. É preciso fazê-lo, mas conforme Cortella (2015), fazê-lo sozinho não consigo, não tenho potência. Para gerar potência, eu tenho que me agregar a outros que queiram fazer. "Não são todos, não é o tempo todo, mas também não é ninguém, nunca. Porque não sou só eu que penso desse modo". (CORTELLA, 2015, p.46). 
CITELLI, A. O.; COSTA, M. C. C. (org.), Educomunicação: construindo uma nova área de conhecimento. São Paulo: Paulinas, 2011.

lo:

Comunicação e Educação. A linguagem em movimento. 3 ed. São Pau-

Editora Senac São Paulo, 2004.

CORTELLA, Mario Sergio. Educação, Convivência e Ética. 2015. Cortez Editora. São Paulo: SP.

FISCHER, Rosa Maria Bueno. Televisão \& educação: fruir e pensar a TV. 3. ed. Belo Horizonte: Autêntica, 2005.

FRANTZ, Walter. Educação e cooperação:práticas que se relacionam.Sociologias, n. 6 , p.242-264, dez., 2001

FRANTZ, W. O Cooperativismo e a Prática Cooperativa. In: Perspectiva Econômica, Ano XIX, n 51, Série Cooperativismo n 16, p.53-70. São Leopoldo: UNISINOS, 1985.

co.

Da necessidade de um pensamento complexo. IN: MARTINS, Francis-

Educação e poder na racionalidade da cooperação. In: PerspectivaEconômica, vol. 38, n 121 , Série Cooperativismo n ${ }^{5}$ 3, p. 15-40. São Leopoldo: UNISINOS, 2001.

Razões do cooperativismo moderno. In: O INTERIOR, ano 32, n963, março de 2006, p. 12. Porto Alegre: COOTRAEL - Cooperativa de Trabalhos

Técnicos Especializados.

FREIRE, P. Pedagogia da Autonomia. 29. Ed. São Paulo: Paz e Terra, 1996.

Pedagogia do Oprimido. 42. Ed. Rio de Janeiro: Paz e Terra, 2005.

Pedagogia da Indignação: cartas pedagógicas e outros escritos. São Paulo: UNESP, 2000.

KAPLÚN, Mario. Processos Educativos e Canais de Comunicação. In: Revista Comunicação e Educação, São Paulo: CCA/ECA/USP, n. 14, jan-abr 1999, p. 68-75

Rev.Cad.Comun. Santa Maria, v.22, n.1, art 1, p.29 de 31, jan/abr.2018 
Una pedagogía de la comunicación. Madri, Ediciones de la Torre, 1998.

LÉVY, Pierre. A inteligência coletiva. Por uma antropologia do ciberespaço. $2^{\mathrm{a}}$ ed. São Paulo: Edições Loyola, 1999.

LÉVY, Pierre. Cibercultura. $2^{\text {a }}$ ed. São Paulo: Editora 34, 2000.

LIB NEO, José Carlos. Pedagogia e pedagogos, para quê? São Paulo: Cortez, 1998

LUHMANN, N. (1999), Politique etcomplexité, Paris, Cerf. (Orig: SoziologischeAufklärung IV).

MARQUES, Mario Osorio. Educação/interlocução, Aprendizagem/reconstrução desaberes. Ijuí: Editora Unijuí, 1996.

MORIN, Edgar. A inteligência da complexidade. São Paulo: Petrópolis, 2011.

RADDATZ, Vera Lucia Spacil. Rádio de fronteira: da cultura local ao espaço global. 2009.

Educação e Comunicação para os Direitos Humanos e Comunicação Cultura e Fronteiras. 2015.

SOARES, Ismar de Oliveira. Educomunicação: o conceito, o profissional, a aplicação: contribuições para a reforma o ensino médio. São Paulo: Paulinas, 2011. 


\section{Pâmela Andrade de Moraes}

Jornalista, graduada pela UNIJUÍ - Universidade Regional do Noroeste do Rio Grande Sul, especialista em Marketing e Comunicação Digital na mesma instituição. É mestranda em Desenvolvimento Regional. Pesquisadora sobre Educomunicação e reflexos para a Cidadania. Atualmente coordena o Núcleo de Comunicação e Marketing da URI- Universidade Regional Integrada do Alto Uruguai e das Missões. E-mail: pamela.andrande.moraes@gmail.com

\section{Nelson José Thesing}

Doutorado em Integração Regional pela Universidade Federal de Pelotas UFPel 2012. Pós-Graduação em Administração Estratégica Universidade Regional do Noroeste do Estado do Rio Grande do Sul UNIJUI (1991). Graduação em Filosofia pela UNIJUI (1986). Pró-Reitor da Unijuí Campus de Panambi. Integra o Corpo Docente do Programa de Pós-Graduação Stricto Sensu em Desenvolvimento.

E-mail: nelson.thesing@unijui.edu.br

\section{Lauriane Tramontina Zeni}

Graduada em Comunicação Social - Publicidade e Propaganda pela Universidade de Passo Fundo (2015). Pós-graduanda em Marketing pela Universidade Regional do Noroeste do Estado do Rio Grande do Sul (UNIJUI). Mestranda em Desenvolvimento Regional pela UNIJUÍ. Possui experiência na área profissional de atendimento, planejamento e criação, mídia, operações comerciais, administração e Marketing.

E-mail: laurianetz@hotmail.com

RECEBIDO EM: $18 / 09 / 2017$

ACEITO EM: 27/10/2017 